\title{
Online Parameter Estimation of DC-DC Converter through OPC Communication Channel
}

\author{
Mohammad A Obeidat ${ }^{1}$ \\ Department of Electrical Power and \\ Mechatronics Engineering \\ Tafila Technical University \\ Tafila, Jordan
}

\author{
Malek Al Anani ${ }^{2}$ \\ Instrumentation and Control \\ Engineering Department \\ SEPCO (Samra Electric Power Co.) \\ Amman, Jordan
}

\author{
Ayman M Mansour ${ }^{3}$ \\ Department of Communication \\ Electronics and Computer \\ Engineering, Tafila Technical \\ University, Tafila, Jordan
}

\begin{abstract}
System identification is a very powerful tool for determining the system model and parameters from sets of observable input and output data. Once the system parameters are obtained, the system dynamic behavior, including all the system characteristics (time constant, overshoot, settling time, etc.) can be accessed and evaluated. Despite the difficulty and communication channel lag, online parameter estimation outperforms offline system identification due to the ability to remotely monitor and control the system as well as improve the system's controller, making it more accurate and reliable. With the extreme development in technology, the importance of combining wireless networks with closed automatic control systems has emerged. This connection facilitates communication processes between the different units in the control for remotely controlled of the output. However, there are some errors affecting such system resulted from communication channel, A/D and $D / A$ conversion process, identification process, or the existence of adaptive weight Gaussian noise. In this paper, the errors were investigated using real system, and then a suitable controller was tuned and optimized in order to reduce and eliminate various errors. The results show excellent dynamic behavior of the system under transmitting and receiving process.
\end{abstract}

Keywords-Online parameters estimation; Open Platform Communication; OPC; communication channel; ARMAX model (autoregressive-moving average with exogenous terms); DC-DC Converter; chopper circuit

\section{INTRODUCTION}

Since online system identification has a number of benefits, such as estimating parameters in real time while the system is operating as well as gaining the ability to monitor and operate the system remotely, it also has a number of challenges. These challenges include (1) analog system discretization with the proper sampling time depending on the system dynamics (2) use a communication channel to send and receive data (3) using the regression method to find the new approximate parameters based on the nature of the measured data (4) deploying the identification process algorithm to determine the new estimated parameters (5) fine-tune an appropriate controller to reduce or remove all identification process errors, this paper focuses on the online parameters estimation for a DC-DC chopper circuit by applying the measured input and output data to the identification algorithm via OPC (Open Platform Communication) after being modeled in the form of ARMAX model(autoregressive-moving average with exogenous terms).

\section{DC-DC CHOPPER CIRCUIT MODELS}

The buck-boost type of the DC-DC Converter will be modeled in both continues and discrete domains.

Fig. 1 shows Buck/Boost converter circuit diagram.

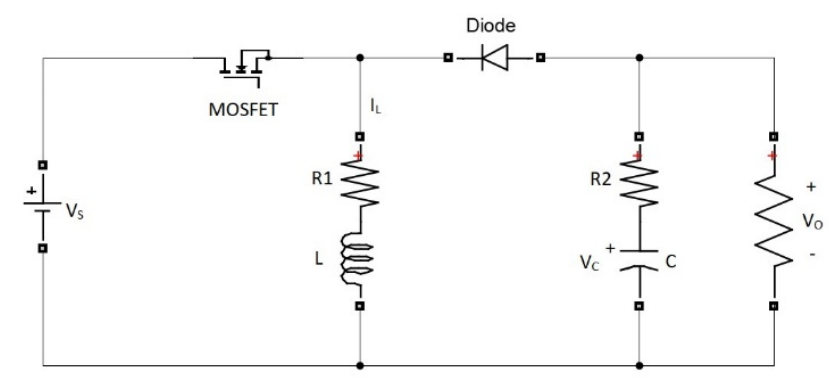

Fig. 1. Buck-Boost Converter Circuit.

Equation 1 describes the relation between input and output voltages which depends on the duty cycle $d$.

$V_{O}=\frac{d}{1-d} * V_{S}$

Mode 1: the switch is short circuit, and the diode is open circuit.

Mode 2: the switch is open circuit, and the diode is short circuit. Assume that the switch and the diode are ideal devices without delay [1, 2]. The state space representation matrices for mode 1 and 2 are:

- Mode 1

$\dot{x}=A_{1} x+B_{1} u$ and $y=C_{1} x+D_{1}$

$$
\begin{array}{ll}
\mathbf{A}_{1}=\left[\begin{array}{cc}
-\frac{R_{a}}{L} & 0 \\
0 & -\frac{1}{C} *\left(\frac{1}{R_{O}+R_{b}}\right)
\end{array}\right] & \mathbf{B}_{1}=\left[\begin{array}{c}
1 / L \\
0
\end{array}\right] \\
\mathbf{C}_{1}=\left[\begin{array}{ll}
0 & 1-\frac{R_{b}}{R_{O}+R_{b}}
\end{array}\right] & \mathbf{D}_{1}=\mathbf{0}
\end{array}
$$

- Mode 2

$\dot{x}=A_{2} x+B_{2} u$ and $y=C_{2} x+D_{2} u$ 

$\mathbf{A}_{2}=\left[\begin{array}{cc}-\left(\frac{R_{a}}{L}+\frac{R_{O} * R_{b}}{L *\left(R_{O}+R_{b}\right)}\right) & -\frac{R_{b}}{L *\left(R_{O}+R_{b}\right)}+\frac{1}{L} \\ -\frac{1}{C} *\left(\frac{R_{O}}{R_{O}+R_{b}}\right) & -\frac{1}{C} *\left(\frac{1}{R_{O}+R_{b}}\right)\end{array}\right]$
$\mathbf{B}_{2}=\left[\begin{array}{l}0 \\ 0\end{array}\right]$
$\mathbf{C}_{2}=\left[\begin{array}{ll}-\frac{\left(R_{O} * R_{b}\right)}{R_{O}+R_{b}} & 1-\frac{R_{b}}{R_{O}+R_{b}}\end{array}\right]$
$\mathbf{D}_{2}=\mathbf{0}$

Mode 1 for Buck/Boost converter is valid for $d T_{S}$ and mode 2 is valid for $(1-d) T_{S}$, where $\mathrm{T}_{\mathrm{s}}$ is the sampling period. After combining both modes equations using averaging technique and divide them by sampling period $T_{S}$, the system block diagram for the Buck/Boost circuit is shown in Fig. 2 $[3,4]$.

In order to study the effect of disturbance on the system output, then MISO (Multi-input single output) system can be presented as two transfer functions, first one describes the relation between first input which is the disturbance and the output voltage, and the other transfer function describes the relation between the second input which is the reference voltage, and the output voltage [5-14]. Fig. 3 shows the MISO block diagram.

Laplace Transform is a useful tool for solving differential equations and analyzing analog systems. It enables us to examine stability through the use of simple pole-zero plots and to describe frequency response of systems through factorization. The $\mathrm{Z}$ Transform is a similar tool that can be used with digital signals. It saves us a lot of time manipulating difference equations. It will assist you in understanding the behavior and stability of a digital system.

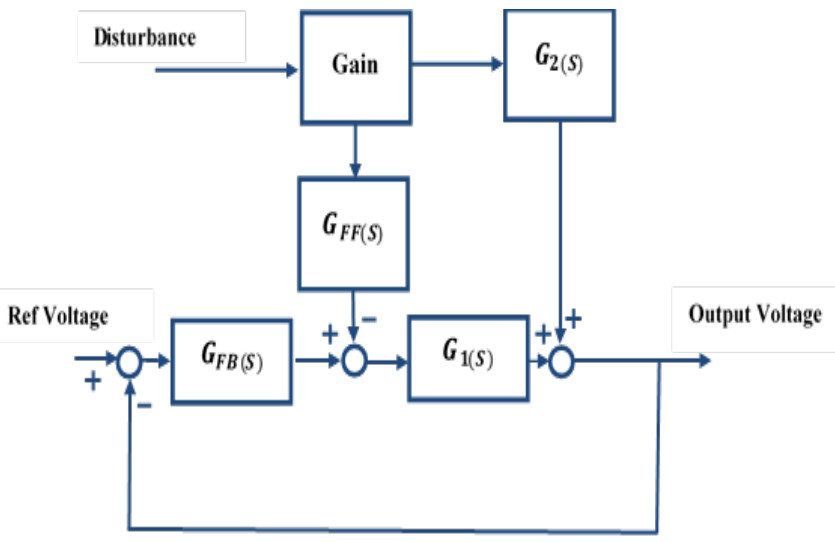

Fig. 2. Buck/Boost Circuit Block Diagram.

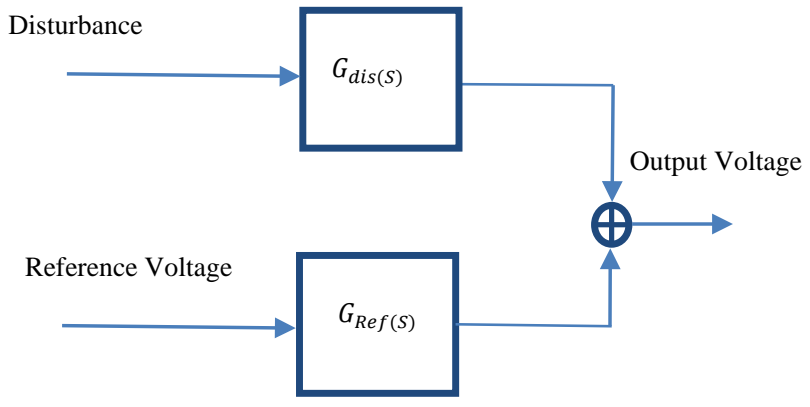

Fig. 3. MISO Block Diagram.
The unilateral Z-Transform of a digital sequence $x n$ is given by.

$Z\left(x_{n}\right)=X(z)=\sum_{n=0}^{\infty} x_{n} z^{-n}$

The discrete state space model is:

$x(k+1)=G x(k)+H u(k)$

$y(k)=C x(k)+D u(k)$

Table I shows the transformation from continuous to discrete.

TABLE I. TRANSFORMATION FROM CONTINUOUS TO DISCRETE

\begin{tabular}{|l|l|}
\hline Continuous & discrete \\
\hline$A x(t)$ & $G x(k)$ \\
\hline$B u(t)$ & $H u(k)$ \\
\hline $\mathrm{C}$ & $\mathrm{C}$ \\
\hline $\mathrm{D}$ & $\mathrm{D}$ \\
\hline
\end{tabular}

The pulse transfer function will be obtained as following:

$\frac{Y(z)}{U(z)}=C(z I-G)^{-1} H+D$

The structure of the Auto Regression Exogenous ARX model can be written as follows:

$A(q) y(t)=B(q) u(t-n k)+e(t)$

Where $A(q)$ and $B(q)$ are defined by:

$A(q)=1+a_{1} q^{-1}+\cdots+a_{n q} q^{-n a}$

$B(q)=b_{1}+b_{2} q^{-1}+\cdots+b_{n b} q^{-n b+1}$

where, $u(t)$ and $y(t)$ are respectively, the input and the output of the system, "t" is time unit, and q-1 represent the delay operator, $[q u(k)=u(k-1)]$.

\section{HARDWARE AND SOFTWARE CONFIGURATION THROUGH OPC COMMUNICATION CHANNELS}

This section illustrates experiment and hardware as well as the software configuration, the components of the real experiment are: Tow computers with network interface card (NIC), Ethernet cable cat5 with Rj45 connecters in both side And an Ethernet switch. Tow computers have been used here to make the identification process more realistic, the data are being transferred from one to the other and then received again.

OPC is a compatibility framework for transferring data securely and reliably in the industrial automation and other industries. It is platform that irrelevant and ensures a smooth flow of data between devices from various manufacturers, and OPC; it is based on the client server model as shown in Fig. 4. [15-18].

The OPC software used in this paper is KEPSERVER, this platform's design enables users to connect, manage, monitor, and control various automation devices and software applications via a single user interface [19]. 


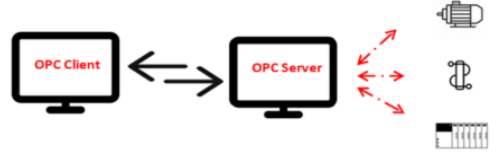

Fig. 4. OPC Client and Server.

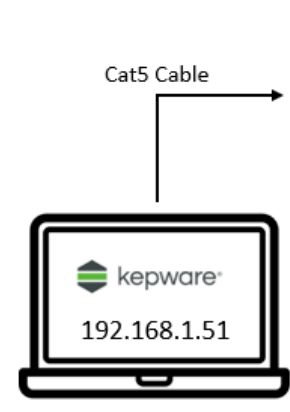

Computer 2
192.168.1.1

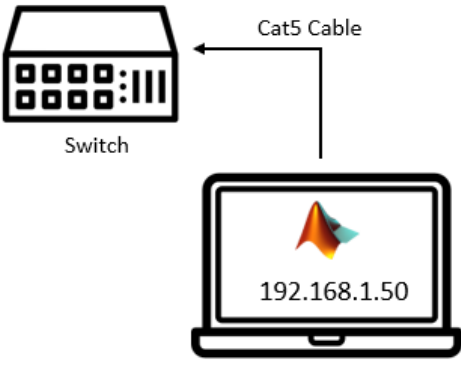

Computer1
Fig. 5. Software and Hardware Topology.

Each one of the computers must be given a specific IP address through the Ethernet switch, one of the computers will be the OPC server "KRPSERVER" [20] and the other computer will be the OPC client "MATLAB" Fig. 5 shows the hardware and software topology [21].

As you can see from Fig. 5, both computers must be in same subnet mask OPC Client - computer 1 is configured with “192.168.1.50” IP address and OPC Server - computer 2 is configured with “192.168.1.51” IP address.

\section{RESUlTS AND DisCUSSION}

The effect of each identification factor, including sampling time $T_{s}$, regression model type, number of parameters in $A(q)$ and $\mathrm{B}(\mathrm{q})$, OPC communication channel effect, and the effect of adding noise to the input disturbance signal, will be investigated. The values of the DC-DC Buck/Boost converter circuit parameters are shown in the Table II.

The continuous transfer functions of the block diagram shown in Fig. 2 become:

$\mathrm{G}_{1}(\mathrm{~s})$ between disturbance and Output voltage.

$G_{1}(s)=\frac{0.74527(s+7.5 e 04)(s-1616)}{\left(s^{2}+227.2 s+2.085 e 05\right)}$

$\mathrm{G}_{2}(\mathrm{~s})$ between $\hat{u}$ and $\hat{y}$

$G_{2}(s)=\frac{-6.995(s+5.757 e 04)}{\left(s^{2}+227.2 s+2.085 e 05\right)}$

The feedback controller $\mathrm{G}_{\mathrm{FB}}(\mathrm{s})$ :

$G_{F B}(s)=\frac{S+1789}{S+7.757 e 04}$

The feedforward controller $\mathrm{G}_{\mathrm{FF}}(\mathrm{s})$ :

$G_{F F}(s)=\frac{-0.33}{S}$
TABLE II. BUCK-BOOST CIRCUIT PARAMETERS

\begin{tabular}{|l|l|}
\hline The parameter & The value \\
\hline$\overline{V_{I N}}$ & $40 \mathrm{~V}$ \\
\hline $\mathrm{L}$ & $2.85^{*} 10^{-3} \mathrm{H}$ \\
\hline $\mathrm{C}$ & $193^{*} 10^{-6} \mathrm{~F}$ \\
\hline $\mathrm{R}_{1}$ & $0.09 \mathrm{ohm}$ \\
\hline $\mathrm{R}_{2}$ & $0.09 \mathrm{ohm}$ \\
\hline $\mathrm{R}_{\mathrm{O}}$ & $27.9 \mathrm{ohm}$ \\
\hline $\bar{d}$ & $2 / 3$ \\
\hline Fs & $60 \mathrm{HZ}$ \\
\hline
\end{tabular}

All transfer functions will be converted to discrete form depending on the sampling time Ts. Each value of Ts gives a specific pulse transfer function, assuming Ts $=0.001$ second such that:

$\mathrm{G}_{1}(\mathrm{z})$ between $\hat{d}$ as input and $\hat{y}$ as the output in $\mathrm{Z}$ domain:

$G_{1}(z)=\frac{0.74527(z+11.52)(z-7.534)}{\left(z^{\wedge} 2+1.613 z+0.7968\right)}$

$\mathrm{G}_{2}(\mathrm{z})$ between $\hat{u}$ as input and $\hat{y}$ as the output in $\mathrm{Z}$ domain:

$G_{2}(z)=\frac{-0.1898(z+0.8653)}{\left(z^{\wedge} 2+1.613 z+0.7968\right)}$

The feedback controller pulse transfer function $\mathrm{G}_{\mathrm{FB}}(\mathrm{z})$ :

$G_{F B}(z)=\frac{Z-0.9689}{z-9.941 e-26}$

The feedforward controller pulse transfer function $\mathrm{G}_{\mathrm{FF}}(\mathrm{z})$ :

$G_{F F}(z)=\frac{-0.00033}{z-1}$

Fig. 6 shows the online identification process with all its steps, the blue dashed line is the OPC communication channel, while the black line indicates the MATLB system signal.

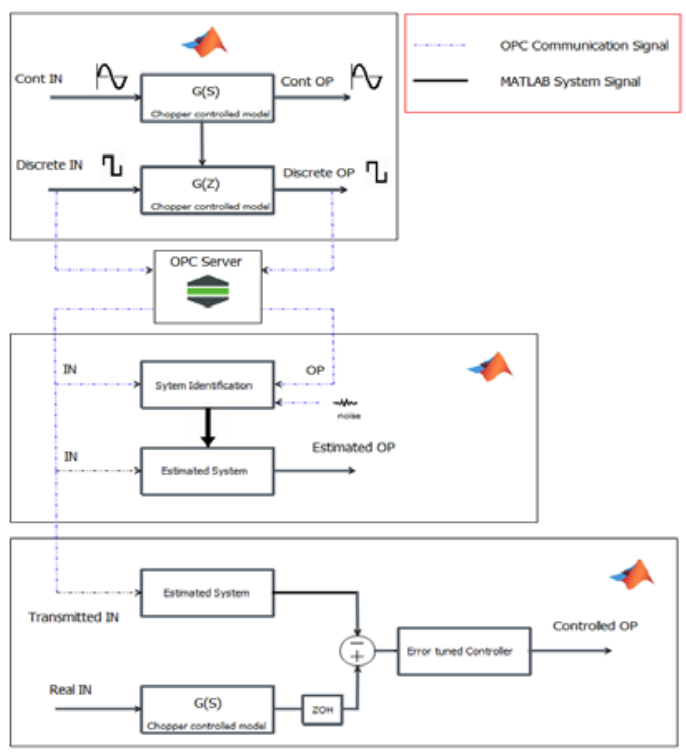

Fig. 6. Identification Process System Block Diagram. 


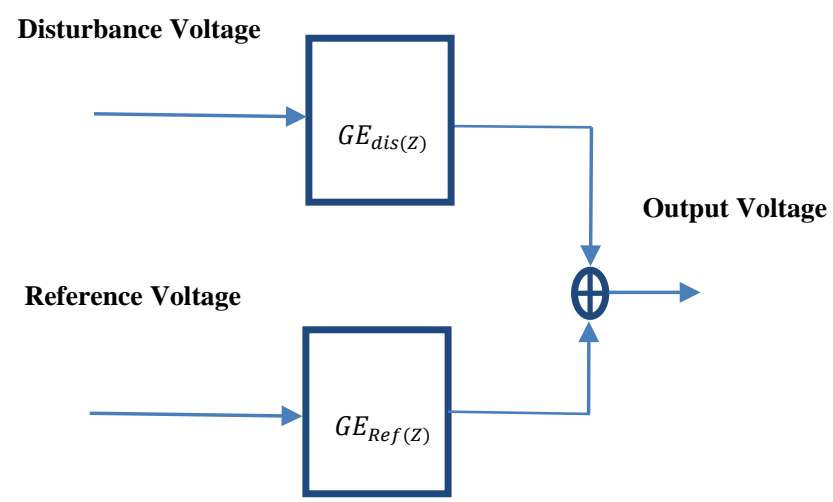

Fig. 7. Estemated Transfer Functions.

After the parameter's estimation of $G_{\operatorname{dis}(S)}$ and $G_{\operatorname{Ref}(S)}$ new estimated transfer functions are obtained $G E_{\operatorname{dis}(Z)}$ and $G E_{R e f(Z)}$ as shown in Fig. 7. Where, $G E_{\operatorname{dis}(Z)}$ describe the relation between first input (disturbance) and output, and $G E_{R e f(Z)}$, describe the relation between second input (disturbance) and output.

\section{A. Sampling Time Ts}

In this section, sampling time will be investigated, and the effect of changing Ts on the identification process will be determined, the parameters value for the DC-DC Converter will be as in the Table II. The identification parameters are shown in Table III.

TABLE III. CONSTANT IDENTIFICATION FACTOR RELATED TO VARYING TS

\begin{tabular}{|l|l|}
\hline The parameter & The value \\
\hline Regression type & ARMAX \\
\hline Regression parameter & $\begin{array}{l}\mathrm{A}(\mathrm{q})=3 \\
\mathrm{~B}(\mathrm{q})=3\end{array}$ \\
\hline OPC & $\begin{array}{l}\text { Scan Rate = same as Ts } \\
\text { Communication remotely via ethernet } \\
\text { cable }\end{array}$ \\
\hline Noise & No noise \\
\hline
\end{tabular}

But sampling time Ts will be varying, the examples below will explain this methodology.

\section{a) Example 1}

In this example the sampling time will assumed to be 0.1 second, Fig. 8 shows the continues OP (output) and Discrete OP (output).

The estimated parameters for both transfer function $G E_{d i s(Z)}$ and $G E_{R e f(Z)}$ are shown in Table IV.
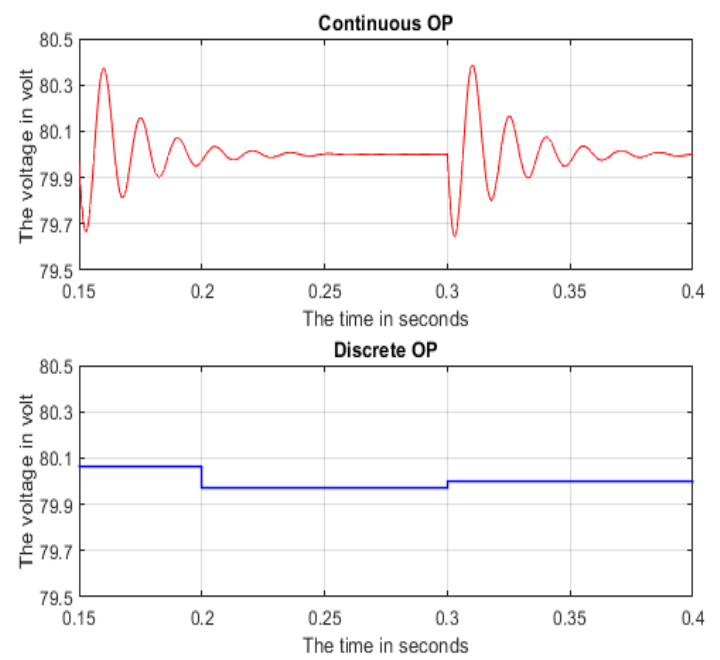

Fig. 8. Continuous and Discrete Outputs related to 0.1 Second Sampling Time.

Fig. 9 shows the Estimated OP(Output).

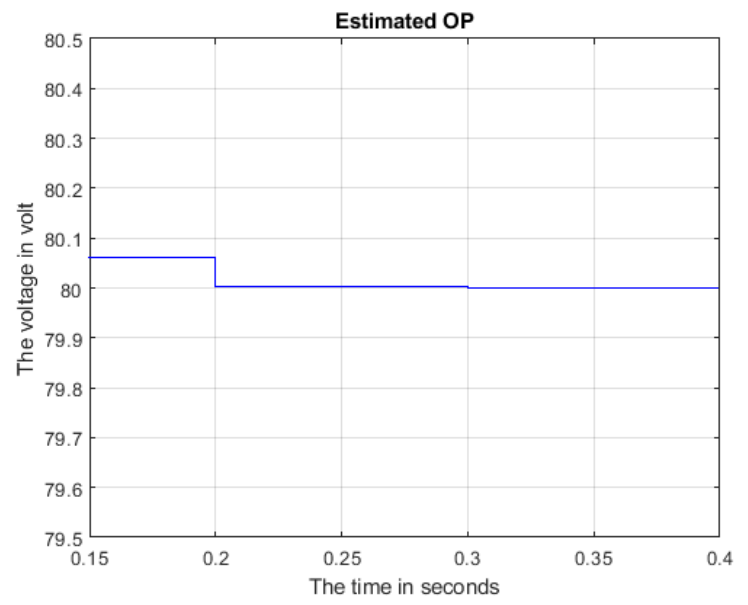

Fig. 9. Estimated Output related to 0.1 Second Sampling Time.

TABLE IV. ESTIMATED PARAMETERS RELATED TO 0.1 SECOND SAMPLING TIME

\begin{tabular}{|c|l|l|l|l|}
\hline \multirow{2}{*}{ q-operator } & \multicolumn{3}{|c|}{ Estimated parameters in both transfer functions } \\
\cline { 2 - 5 } & \multicolumn{2}{|c|}{$G E_{\text {dis }(q)}$} & \multicolumn{2}{c|}{$G E_{\text {Ref }(q)}$} \\
\cline { 2 - 5 } & $A(q)$ & $B(q)$ & & \multicolumn{2}{c|}{$A(q)$} & \multicolumn{1}{c|}{$B(q)$} \\
\hline$q^{0}$ & 1 & 0 & 1 & 0 \\
\hline$q^{-1}$ & $-9.64 \mathrm{E}-08$ & $-2.37 \mathrm{E}-05$ & $3.6 \mathrm{E}-04$ & 1.001 \\
\hline$q^{-2}$ & $2.2 \mathrm{E}-016$ & $2.2 \mathrm{E}-016$ & $2.6 \mathrm{E}-05$ & $-3.6 \mathrm{E}-4$ \\
\hline$q^{-3}$ & $2.2 \mathrm{E}-016$ & $2.2 \mathrm{E}-016$ & $2.2 \mathrm{E}-16$ & $-2.6 \mathrm{E}-05$ \\
\hline
\end{tabular}




\section{b) Example 2}

In this example the sampling time will assumed to be 0.01 second, Fig. 10 shows the continues OP and Discrete OP.
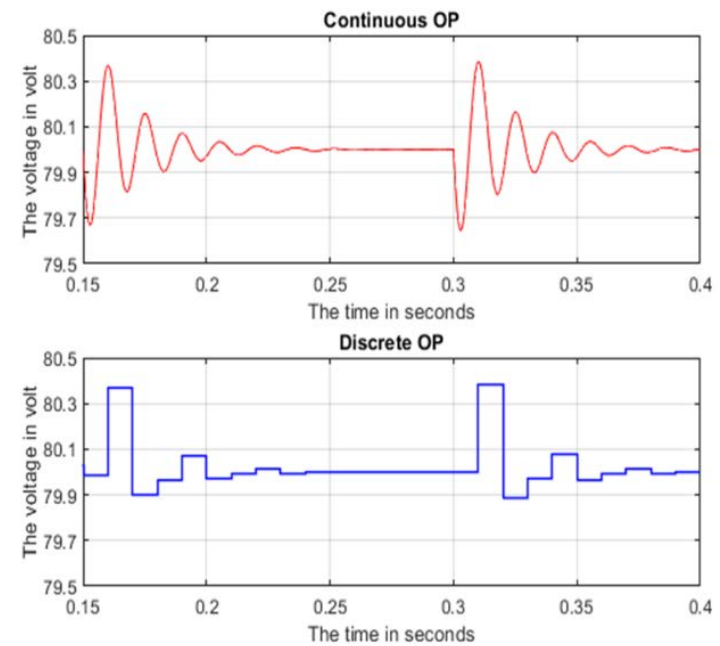

Fig. 10. Continuous and Discrete Outputs related to 0.01 second Sampling Time.

Fig. 11 shows the Estimated OP.

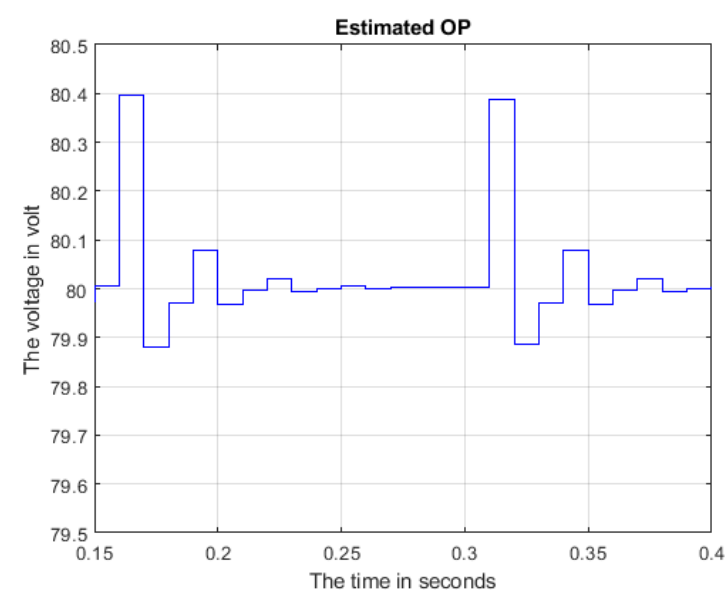

Fig. 11. Estimated Output related to 0.01 Second Sampling Time.

The estimated parameters for both transfer function $G E_{\operatorname{dis}(Z)}$ and $G E_{R e f(Z)}$ are shown in Table V.

TABLE V. ESTIMATED PARAMETERS RELATED TO 0.01 SECOND SAMPLING TIME

\begin{tabular}{|c|c|c|c|c|}
\hline \multirow{3}{*}{ q-operator } & \multicolumn{4}{|c|}{ Estimated parameters in both transfer functions. } \\
\hline & \multicolumn{2}{|c|}{$G E_{\operatorname{dis}(q)}$} & \multicolumn{2}{|c|}{$G E_{R e f(q)}$} \\
\hline & $A(q)$ & $B(q)$ & $A(q)$ & $B(q)$ \\
\hline$q^{0}$ & 1 & 0 & 1 & 0 \\
\hline$q^{-1}$ & 0.3443 & 0.048189 & 0.3356 & 0.8474 \\
\hline$q^{-2}$ & 0.1861 & -0.04588 & 0.2025 & 0.2453 \\
\hline$q^{-3}$ & -0.1129 & -0.002297 & -0.1114 & 0.334 \\
\hline
\end{tabular}

\section{c) Example 3}

In this example the sampling time will assumed to be .001 second Fig. 12 shows the continues OP and Discrete OP:
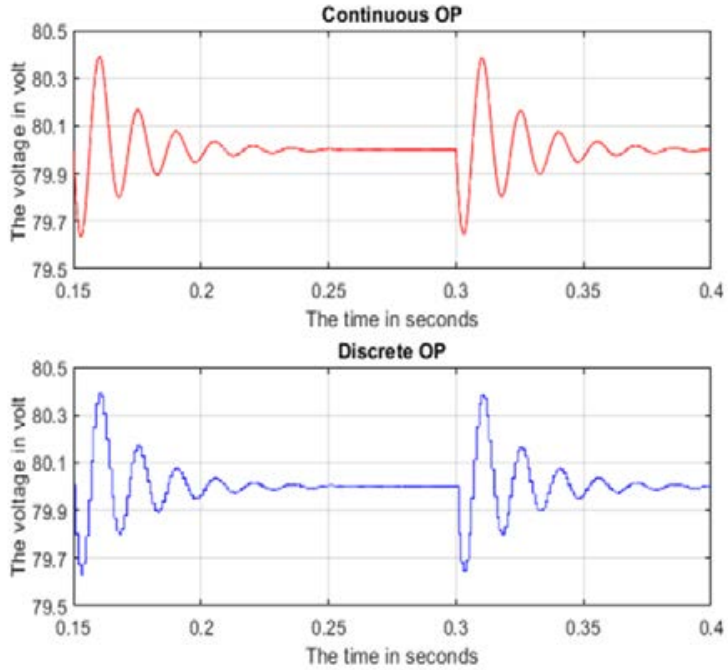

Fig. 12. Continuous and Discrete Outputs related to 0.001 Second Sampling Time.

Fig.13 shows the Estimated OP.

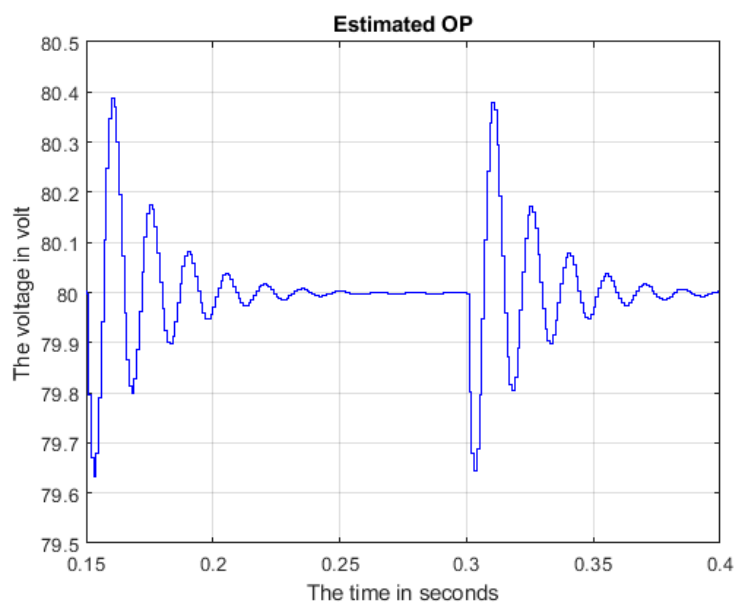

Fig. 13. Estimated Output related to 0.001 second sampling Time.

The estimated parameters for both transfer function $G E_{\operatorname{dis}(Z)}$ and $G E_{R e f(Z)}$ are shown in Table VI.

TABLE VI. ESTIMATEd PARAMETERS RELATED TO 0.001 SECOND SAMPLING TIME

\begin{tabular}{|c|c|c|c|c|}
\hline \multirow{3}{*}{ q-operator } & \multicolumn{4}{|c|}{ Estimated parameters in both transfer functions. } \\
\hline & \multicolumn{2}{|c|}{$G E_{d i s(q)}$} & \multicolumn{2}{|c|}{$G E_{R e f(q)}$} \\
\hline & $A(q)$ & $B(q)$ & $A(q)$ & $B(q)$ \\
\hline$q^{0}$ & 1 & 0 & 1 & 0 \\
\hline$q^{-1}$ & -2.657 & -0.0244 & -2.617 & -0.0029 \\
\hline$q^{-2}$ & 2.505 & 0.04952 & 2.434 & 0.01425 \\
\hline$q^{-3}$ & -0.8339 & -0.02513 & -0.7972 & 0.00864 \\
\hline
\end{tabular}




\section{- Discussion}

The conclusion is that as the sampling time increases, the identification error decreases and the identification process becomes more accurate, because as the sample time increases, more data from the system is analyzed and the identification loop has more data to estimate the parameter. In the case of Ts $=0.001$, we have 401 sets of values, which is sufficient to accurately estimate the parameter, whereas when Ts $=0.01$, we only have 41 sets of values, which is insufficient to estimate the parameters. On the other hand, choosing Ts to be very low will take a long time to complete the identification process, In the worst-case scenario, Ts=0.1 second leads to poor identification because the system completes its dynamic behavior and reaches steady state in 0.15 second, because when Ts=0.1 second, only two values are generated to describe the complete system's behavior, which is insufficient. Assuming Ts $=0.001$, we have two advantages.

1) 1. provides a sufficient set of data to enable accurate identification.

2) It takes an acceptable amount of time, not too long but also not too fast.

Conclusion is that assuming Ts $=.001$ is better for this system, considering the response time and dynamic behavior for our system (DC Converter circuit), Table VII compares the sampling time with the system characteristic (overshoot, response time... etc.), delay time, and the identification error in general, also the ability to tune a controller to overcome the identification error.

Table VIII shows that as much as the sampling time increase high delay is added, extremely high identification error and the system characteristic and be measured or obtained.

\section{B. Number of Parameters}

The effect of changing the number of parameters will be investigated in this section, and thus the effect of changing the number of parameters on the identification process will be determined; the parameters value for the DC-DC Converter will be as shown in Table II.

TABLE VII. SAMPLING Time EFFECT TO THE IDENTIFICATION PROCESS

\begin{tabular}{|l|l|l|l|l|}
\hline TS(Second) & $\begin{array}{l}\text { System } \\
\text { characteristics }\end{array}$ & $\begin{array}{l}\text { Identification } \\
\text { error }\end{array}$ & $\begin{array}{l}\text { Controller } \\
\text { tuning }\end{array}$ & $\begin{array}{l}\text { Delay } \\
\text { time }\end{array}$ \\
\hline 0.1 & $\begin{array}{l}\text { Cannot be } \\
\text { obtained }\end{array}$ & $\begin{array}{l}\text { Extremely } \\
\text { high }\end{array}$ & $\begin{array}{l}\text { No } \\
\text { controller }\end{array}$ & $\begin{array}{l}\text { Very } \\
\text { Hight } \\
\text { more than } \\
0.2 \\
\text { second }\end{array}$ \\
\hline 0.01 & $\begin{array}{l}\text { Can be } \\
\text { obtained with } \\
\text { high error }\end{array}$ & Hight & $\begin{array}{l}\text { Controller } \\
\text { can be } \\
\text { tuned but } \\
\text { error will } \\
\text { still high }\end{array}$ & \begin{tabular}{l}
$\begin{array}{l}\text { Hight } \\
\text { around } \\
0.02 \\
\text { second }\end{array}$ \\
\hline 0.001
\end{tabular} \\
& $\begin{array}{l}\text { Can be } \\
\text { obtained } \\
\text { highly } \\
\text { accurate }\end{array}$ & Low & $\begin{array}{l}\text { Controller } \\
\text { can be } \\
\text { tuned, and } \\
\text { the error } \\
\text { will be } \\
\text { reduced }\end{array}$ & $\begin{array}{l}\text { Low } \\
\text { around } \\
0.002 \\
\text { second }\end{array}$ \\
\hline
\end{tabular}

TABLE VIII. CONSTANT IDENTIFICATION FACTOR RELATED TO VARYING PARAMETERS NUMBER

\begin{tabular}{|l|l|}
\hline The parameter & The value \\
\hline Regression type & ARMAX \\
\hline Sampling Time & Ts = 0.001 \\
\hline OPC & $\begin{array}{l}\text { Scan Rate }=\text { same as Ts } \\
\text { Communication remotely via ethernet } \\
\text { cable }\end{array}$ \\
\hline Noise & No noise \\
\hline
\end{tabular}

The identification parameters are shown in Table VIII.

But the parameters number will be varying, the examples below will explain this methodology.

\section{a) Example 4}

In this example the parameters number will assumed to be two in both $A(q)$ and $B(q)$, referring to Fig. 12 the continues OP and Discrete OP are shown.

Fig. 14 shows the Estimated OP.

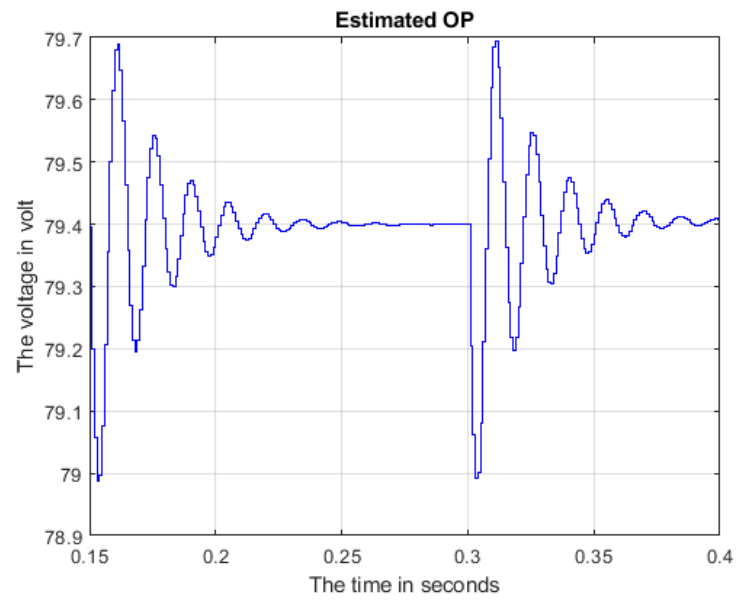

Fig. 14. Estimated OP related to Two Parameters.

The estimated parameters for both transfer function $G E_{\operatorname{dis}(Z)}$ and $G E_{\operatorname{Ref}(Z)}$ are shown in Table IX.

TABLE IX. Estimated Parameters Related to Two PARAMETERS

\begin{tabular}{|c|l|l|l|l|}
\hline \multirow{2}{*}{ q-operator } & \multicolumn{3}{|c|}{ Estimated parameters in both transfer functions. } \\
\cline { 2 - 5 } & \multicolumn{2}{|c|}{$G E_{\text {dis }(q)}$} & \multicolumn{2}{c|}{$G E_{\text {Ref }(q)}$} \\
\cline { 2 - 5 } & \multicolumn{2}{|c|}{$A(q)$} & \multicolumn{1}{|c|}{$B(q)$} & \multicolumn{2}{|c|}{$A(q)$} & $B(q)$ \\
\hline$q^{0}$ & 1 & 0 & 1 & 0 \\
\hline$q^{-1}$ & -1.732 & -0.02445 & -1.786 & -0.0029 \\
\hline$q^{-2}$ & 0.9079 & 0.02445 & 0.8227 & 0.03975 \\
\hline
\end{tabular}

b) Example 5

In this example the parameters number will assumed to be three in both $\mathrm{A}(\mathrm{q})$ and $\mathrm{B}(\mathrm{q})$, referring to Fig. 12 the continues OP and Discrete OP are shown.

Fig. 15 shows the Estimated OP. 


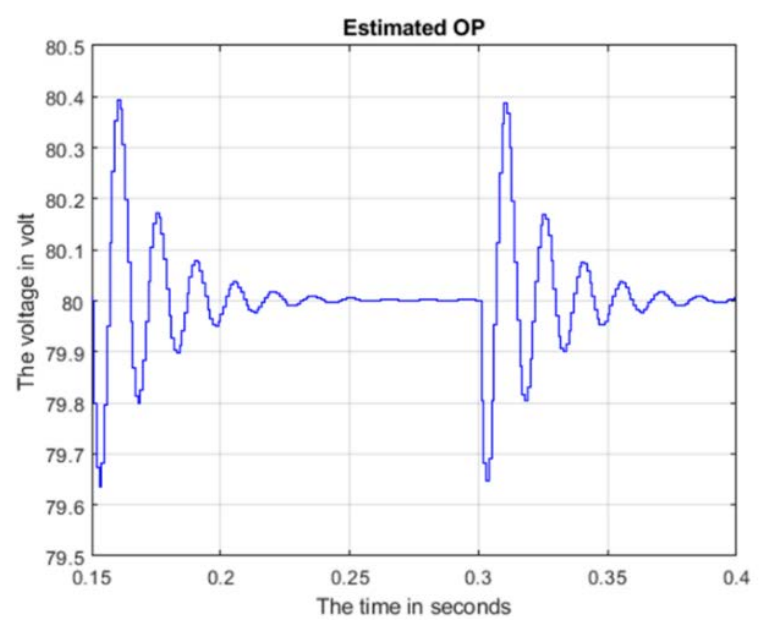

Fig. 15. Estimated OP related to Three Parameters.

Table $\mathrm{X}$ shows the estimated parameters in both transfer functions.

TABle X. Estimated Parameters Related to Three Parameters

\begin{tabular}{|c|l|l|l|l|}
\hline \multirow{2}{*}{ q-operator } & \multicolumn{2}{|c|}{ Estimated parameters in both transfer functions. } \\
\cline { 2 - 5 } & \multicolumn{2}{|c|}{$G E_{\text {dis(q) }}$} & \multicolumn{2}{c|}{$G E_{\text {Ref }(q)}$} \\
\cline { 2 - 5 } & $A(q)$ & $B(q)$ & \multicolumn{1}{c|}{$A(q)$} & $B(q)$ \\
\hline$q^{0}$ & 1 & 0 & 1 & 0 \\
\hline$q^{-1}$ & -2.657 & -0.0244 & -2.617 & -0.0029 \\
\hline$q^{-2}$ & 2.505 & 0.04952 & 2.434 & 0.01425 \\
\hline$q^{-3}$ & -0.8339 & -0.02513 & -0.7972 & 0.00864 \\
\hline
\end{tabular}

\section{- Discussion}

A conclusion is reached, which is that as the number of parameters increases, the identification error decreases and the identification process becomes more accurate, because as the number of parameters increases, more of the system's properties and characteristics can be measured. When the number of parameters is assumed to be two, thigh error is introduced into the system, and these two parameters cannot describe the system dynamic. However, when the number of parameters is three, the induced error is very low and can be ignored, resulting in good identification with all the original system properties being obtained well. On the other hand, as the number of parameters increases, more complexity is added to the system, making tuning a controller to reduce identification errors more difficult, in this case, selecting three parameters is sufficient, and the induced error is very low. Conclusion is that assuming number of parameters to be three is the better choice as it leads to good identification and low complexity.

Table XI compares the number of parameters with the system characteristic (overshoot, response time ... etc.), Degree of complexity, the identification error in general and the ability to tune a controller to reduce or eliminate the identification errors.
TABLE XI. NUMBER OF PARAMETERS EFFECT TO THE IDENTIFICATION PROCESS

\begin{tabular}{|l|l|l|l|l|}
\hline $\begin{array}{l}\text { Number of } \\
\text { parameters }\end{array}$ & $\begin{array}{l}\text { System } \\
\text { characteristics }\end{array}$ & $\begin{array}{l}\text { Identification } \\
\text { error }\end{array}$ & $\begin{array}{l}\text { Controller } \\
\text { tuning }\end{array}$ & $\begin{array}{l}\text { Degree of } \\
\text { complexity }\end{array}$ \\
\hline 2 & $\begin{array}{l}\text { Can be } \\
\text { obtained with } \\
\text { high error }\end{array}$ & high & $\begin{array}{l}\text { No } \\
\text { controller }\end{array}$ & $\begin{array}{l}\text { Low } \\
\text { complexity }\end{array}$ \\
\hline 3 & $\begin{array}{l}\text { Can be } \\
\text { obtained with } \\
\text { low error }\end{array}$ & Low & $\begin{array}{l}\text { Controller } \\
\text { can be } \\
\text { tuned, and } \\
\text { the error } \\
\text { will be } \\
\text { reduced }\end{array}$ & $\begin{array}{l}\text { Low } \\
\text { complexity }\end{array}$ \\
\hline
\end{tabular}

Table XI shows that as the number of parameters increases, good identification is obtained, but the system becomes very complex, so choosing three parameters results in an acceptable error and a low degree of complexity. Making a system with a low degree of complexity is preferable to making a system with a high degree of complexity as long as the error remains within acceptable limits.

\section{Regression Model Type}

In this section, the effect of changing the regression model will be investigated, and the effect of changing the model type either ARMAX or ARX to the identification process will be determined, the parameters value for the DC-DC Converter will be as in the Table II, the identification parameters is shown in Table XII.

TABLE XII. CONSTANT IDENTIFICATION FACTOR RELATED TO VARYING PARAMETERS NUMBER

\begin{tabular}{|l|l|}
\hline The parameter & The value \\
\hline Regression parameter & $\begin{array}{l}\mathrm{A}(\mathrm{q})=3 \\
\mathrm{~B}(\mathrm{q})=3\end{array}$ \\
\hline Sampling Time & Ts $=0.001$ \\
\hline OPC & $\begin{array}{l}\text { Scan Rate = same as Ts } \\
\text { Communication remotely via ethernet } \\
\text { cable }\end{array}$ \\
\hline Noise & No noise \\
\hline
\end{tabular}

But the regression model type will be varying, the examples below will explain this methodology.

\section{a) Example 6}

This example will compare the effect of both regression models ARMAX and ARX and the other factors as shown in Table XIV will be constant, Fig. 12 shows the continues OP and Discrete OP:

Fig. 16 shows the Estimated OP for ARMAX \& ARX. 
(IJACSA) International Journal of Advanced Computer Science and Applications,

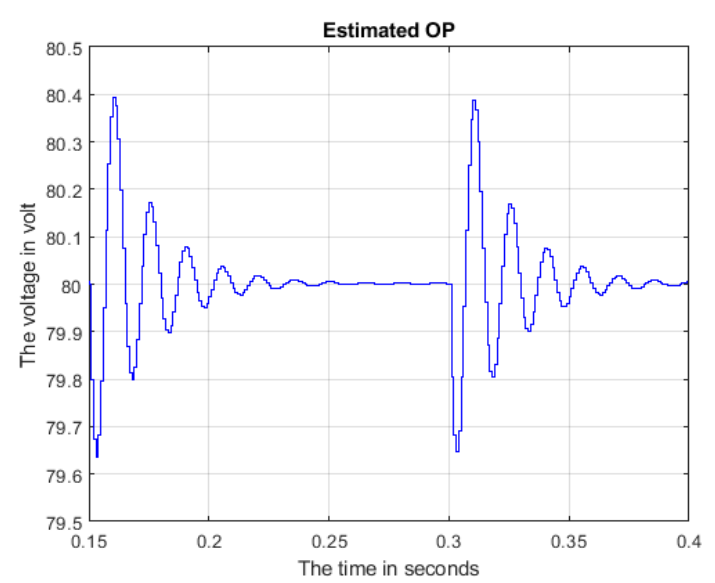

Fig. 16. Estimated OP for Both ARX and ARMAX.

After applying the identification algorithm for ARMAX and ARX, both models give the same parameters in both transfer functions $G E_{\operatorname{dis}(Z)}$ and $G E_{\operatorname{Ref}(Z)}$ as shown in Table XIII.

TABLE XIII. ESTIMATED PARAMETERS IN BOTH ARX AND ARMAX

\begin{tabular}{|c|c|c|c|c|}
\hline \multirow{3}{*}{ q-operator } & \multicolumn{4}{|c|}{ Estimated parameters in both transfer functions } \\
\hline & \multicolumn{2}{|c|}{$G E_{\text {dis }(q)}$} & \multicolumn{2}{|c|}{$G E_{\operatorname{Ref}(q)}$} \\
\hline & $A(q)$ & $B(q)$ & $A(q)$ & $B(q)$ \\
\hline$q^{0}$ & 1 & 0 & 1 & 0 \\
\hline$q^{-1}$ & -2.657 & -0.0244 & -2.617 & -0.0029 \\
\hline$q^{-2}$ & 2.505 & 0.04952 & 2.434 & 0.01425 \\
\hline$q^{-3}$ & -0.8339 & -0.02513 & -0.7972 & 0.00864 \\
\hline
\end{tabular}

- Discussion

After comparing the results of ARX and ARMAX, the results were similar; both models give the same estimated OP as well as the same value of the estimated parameters as shown in Table XIII.

Results above show that either ARX or ARMAX can work properly with low identification error, so choosing either of them has no effect on the identification process; however, from ARMAX concept it would work more efficiently if the system became more complex with a large variation in the input or output signals because it combines the advantages of both MA (moving average) and AR (autoregressive).

\section{OPC Communication Channel}

In this section, the effect of the OPC communication channel will be investigated, the identification process will be working in two modes:

1) Local mode, where no communication channel is used and all the data analyzing will be locally in the same computer and in the same environment which is MATLAB 2020.

2) Remote mode, where the data is transferred and received from one computer to the other in the private network through the OPC communication channel via ethernet cable cat5.

The parameters value for the DC-DC Converter will be as in the Table II, the identification parameters are shown in Table XIV.
TABLE XIV. CONSTANT IDENTIFICATION FACTOR RELATED TO LOCAL AND REMOTE MODES

\begin{tabular}{|l|l|}
\hline The parameter & The value \\
\hline Regression parameter & $\begin{array}{l}\mathrm{A}(\mathrm{q})=3 \\
\mathrm{~B}(\mathrm{q})=3\end{array}$ \\
\hline Sampling Time & Ts $=0.001$ \\
\hline Regression Model & ARMAX \\
\hline Noise & No noise \\
\hline
\end{tabular}

The identification error will be studied in both remote and local mode; also the communication channel effect will be obtained.

\section{a) Example 7}

The local mode identification process will be studied, Fig. 12 shows the continues OP and Discrete OP, Fig. 17 shows the comparison between the Discrete OP and Estimated OP in local mode.

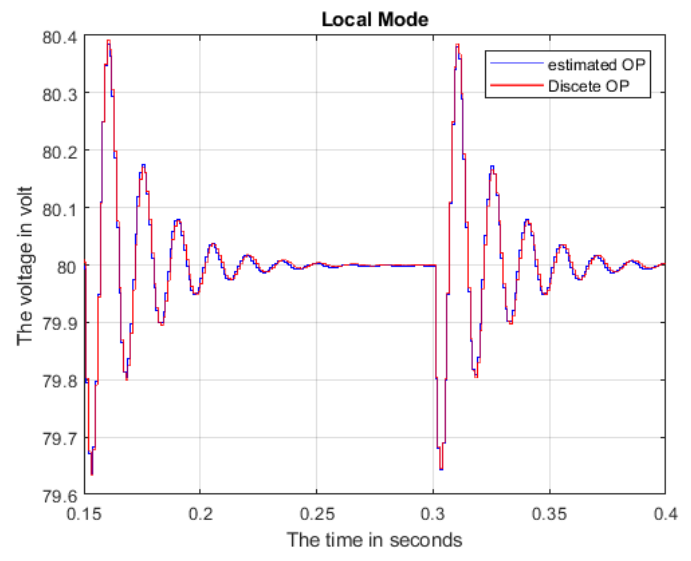

Fig. 17. Estimated OP in Local Mode.

As shown in Fig. 17, the estimated OP is very close to the discrete OP with a very low amount of error and an efficient identification, which is caused by processing the data very quickly with no delays because the local mode does not require sending or receiving data from one computer to another, and no hardwires (Ethernet cable cat5) are used.

The estimated parameters for both transfer function $G E_{\operatorname{dis}(Z)}$ and $G E_{R e f(Z)}$ are shown in Table XV.

TABLE XV. ESTIMATED PARAmeters RELATED to LOCAL Mode

\begin{tabular}{|c|c|c|c|c|}
\hline \multirow{3}{*}{ q-operator } & \multicolumn{4}{|c|}{ Estimated parameters in both transfer functions } \\
\hline & \multicolumn{2}{|c|}{$G E_{\text {dis }(q)}$} & \multicolumn{2}{|c|}{$G E_{R e f(q)}$} \\
\hline & $A(q)$ & $B(q)$ & $A(q)$ & $B(q)$ \\
\hline$q^{0}$ & 1 & 0 & 1 & 0 \\
\hline$q^{-1}$ & -2.65837542 & -0.0244 & -2.6151791 & -0.0029257 \\
\hline$q^{-2}$ & 2.508143613 & 0.0495739 & 2.43228732 & 0.01426002 \\
\hline$q^{-3}$ & -0.8365384 & -0.025169 & -0.7969769 & 0.008797002 \\
\hline
\end{tabular}

b) Example 2

The remote identification process will be studied, Fig. 12 shows the continues OP and Discrete OP, Fig. 18 shows the comparison between the Discrete OP and Estimated OP in remote mode. 


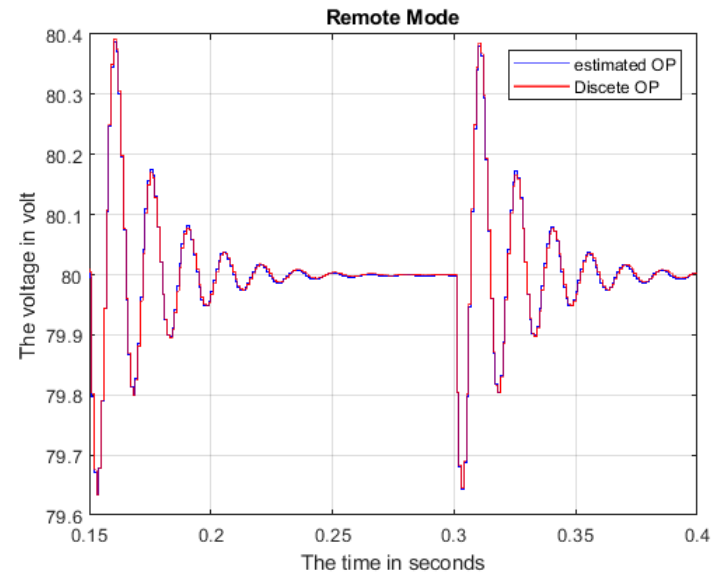

Fig. 18. Estimated OP in Remote Mode.

As shown in Fig. 18, the estimated OP is very close to the discrete OP with very amount error and an efficient identification. Using an OPC communication channel has no effect on the identification process because of the low error, and the communication channel was very fast and accurate due to the Ethernet cat5 high speed rate, high accuracy of the OPC communication channel and high-speed processing units.

The OPC communication channel error is caused by the delay time, as the OPC communication channel transmits the data as a query, it collects the data and convert it to a query then it sends it as packets over the Ethernet Cat5 cable, Due to high processing units and using cable with very high transition speed rate the communication channel does not add high error but rather a very small amount of error caused by the delay time.

Comparing the Discrete output with the received output is the key to determining the communication channel delay error. Fig. 19 shows MATLAB block for this comparison.

Fig. 19 shows MATLAB blocks for the comparing between received OP and Discrete OP, Fig. 20 shows the comparing results.

Fig. 20 shows the communication error, it clears from this figure that there is an error caused by the OPC communication channel.

Because the communication channel error is a delay time error, the best way to test the communication channel's performance is to add the same amount of delay to the discrete OP and then compare these signals again, as shown in Fig. 21.

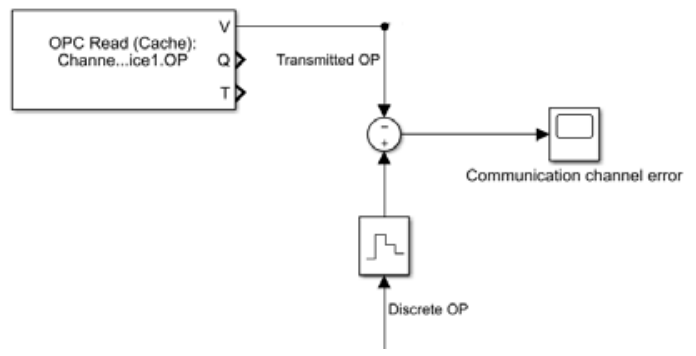

Fig. 19. Discrete and Received Outputs Comparison.

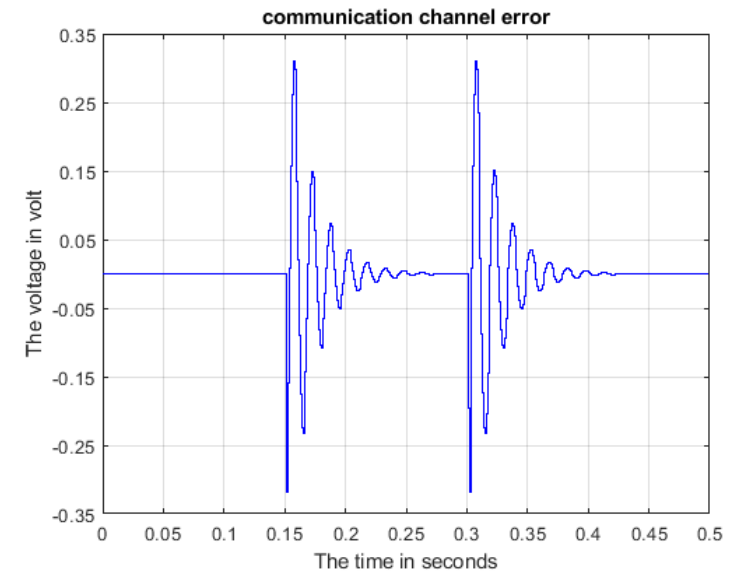

Fig. 20. Communication Error.

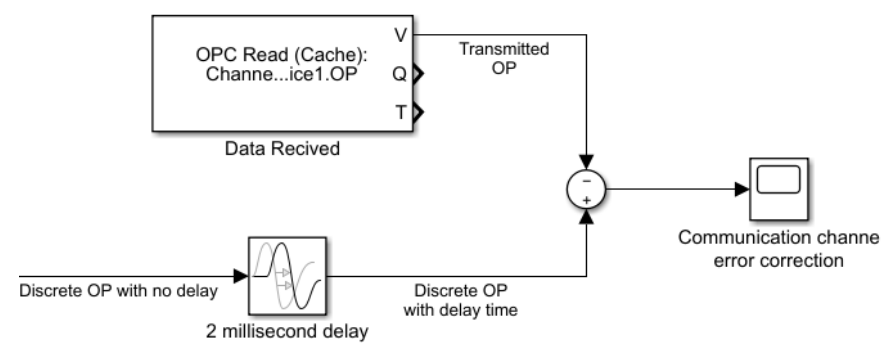

Fig. 21. Example of a Figure Caption.

Fig. 21 shows the MATLAB block ordering to compare the delayed Discrete OP signal with the received OP, Fig. 22 below shows the comparison result.

Fig. 22 shows that the communication channel error has been eliminated by adding 2 millisecond delay time to the discrete OP, as a result of this comparison, the OPC communication channel error is just 2 millisecond delay with neglectable noise, the noise as shown in the figure above are two pulses with very low amplitude the value of the noise amplitude is a power of $-4\left(\times 10^{-4}\right)$ which makes it neglectable and does not affect the identification process, the hardwire cable is the main cause for this noise.

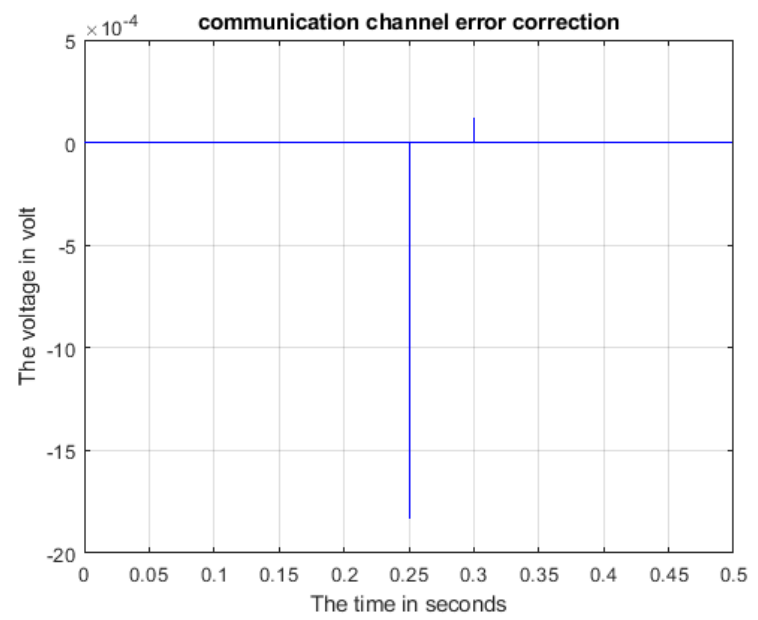

Fig. 22. Delay Time Error Cancellation. 
TABLE XVI. Estimated PARAmeters RELATED to Remote Mode

\begin{tabular}{|c|l|l|l|l|}
\hline \multirow{2}{*}{ q-operator } & \multicolumn{2}{|c|}{$G E_{\text {dis }(q)}$} & \multicolumn{2}{c|}{$G E_{\operatorname{Ref}(q)}$} \\
\cline { 2 - 5 } & $A(q)$ & $B(q)$ & $A(q)$ & \multicolumn{1}{c|}{$B(q)$} \\
\cline { 2 - 5 } & 1 & 0 & 1 & 0 \\
\hline$q^{0}$ & -2.6572643 & -0.024396 & -2.616792 & -0.0029133 \\
\hline$q^{-1}$ & 2.50481665 & 0.0495228 & 2.4338879 & 0.01424647 \\
\hline$q^{-2}$ & -0.833855 & -0.025127 & -0.7971178 & 0.0086445 \\
\hline$q^{-3}$ &
\end{tabular}

The estimated parameters for both transfer function $G E_{d i s(Z)}$ and $G E_{R e f(Z)}$ are shown in Table XVI.

\section{- Discussion}

The remote mode, which uses an OPC communication channel via a hardwire Ethernet cable cat5, results in a good identification process with very low error, as long as the transmitted signal has a short delay time, as a result of using a high-speed rate cable with a high computer processing unit performance, the communication channel error will be very small, and in some cases can be ignored.

Because the remote mode provides low communication channel error, the advantage of using it instead of the local mode is high, due to the remote-control ability that does not exist in the local mode. The conclusion is that using remote mode is better than using the local mode because of the low error presence as well as the ability to remotely control and observe the system via the network.

\section{E. Noisy Input Disturbance Signal}

The effect of changing the noise amplitude and frequency at the input disturbance signal will be investigated in this section, the output signal will be noise free, as will the reference input signal, and thus the effect of changing the noise configuration to the identification process will be determined, The DC-DC Converter parameters will be as shown in Table II.

The identification parameters are shown in Table XVII.

TABLE XVII. CONSTANT IDENTIFICATION FACTOR RELATED NOISY INPUT SIGNAL

\begin{tabular}{|l|l|}
\hline The parameter & The value \\
\hline Regression parameter & $\begin{array}{l}\mathrm{A}(\mathrm{q})=3 \\
\mathrm{~B}(\mathrm{q})=3\end{array}$ \\
\hline Sampling Time & Ts $=0.001$ \\
\hline OPC & $\begin{array}{l}\text { Scan Rate = same as Ts } \\
\text { Communication remotely via ethernet } \\
\text { cable }\end{array}$ \\
\hline Regression model type & ARMAX \\
\hline
\end{tabular}

Fig. 23 shows the MATLAB blocks for the noisy input signal.

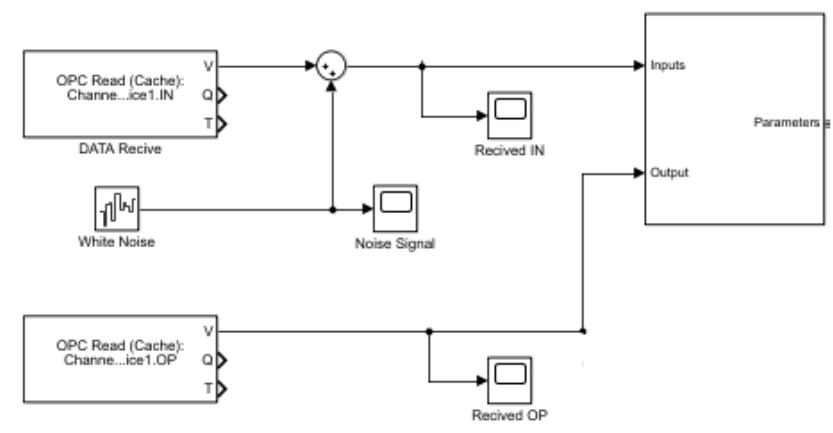

Fig. 23. MATLAB Ordering Blocks for Noisy Input Signal.

As illustrated in Fig. 23 the input signal with adding noise is applied to the identification algorithm, on the other hand the output signal and the reference input signal still noise free signals.

But the noise configuration will be varying, the examples below will explain this methodology.

\section{a) Example 8}

In this example noise will assumed to be 0.01 Power spectral density with $100 \mathrm{~Hz}$, the following Fig. 24 shows the Received communicated noise input signal with 0.01 PSD and $100 \mathrm{HZ}$ frequency compared with the (not communicated signal) MATLAB input signal, the input signal here is the disturbance signal to the converter circuit and the other input which is the reference signal will be noise free.

Fig. 25 shows the Estimated OP and the Discrete OP.

It is clear from Fig. 25 that the estimated OP deviates greatly from the discrete OP, so that as the noise PSD and frequency increase, the identification process efficiency decreases, and high error is added to the system. From Fig. 25, the system characteristics (settling time, overshoot, oscillations number.... etc.) can be measured but with high error.

The estimated parameters for both transfer function $G E_{\text {dis }(Z)}$ and $G E_{R e f(Z)}$ are shown in Table XVIII.
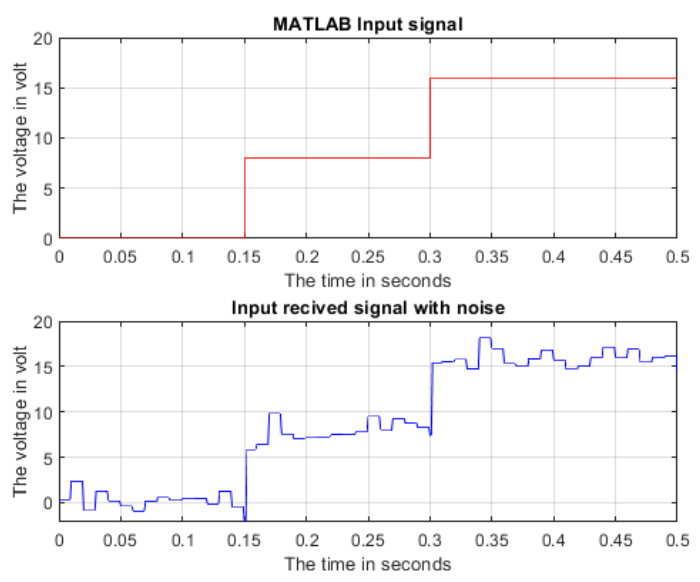

Fig. 24. Noisy Input related to 0.01 PSD and 100 HZ Frequncy. 


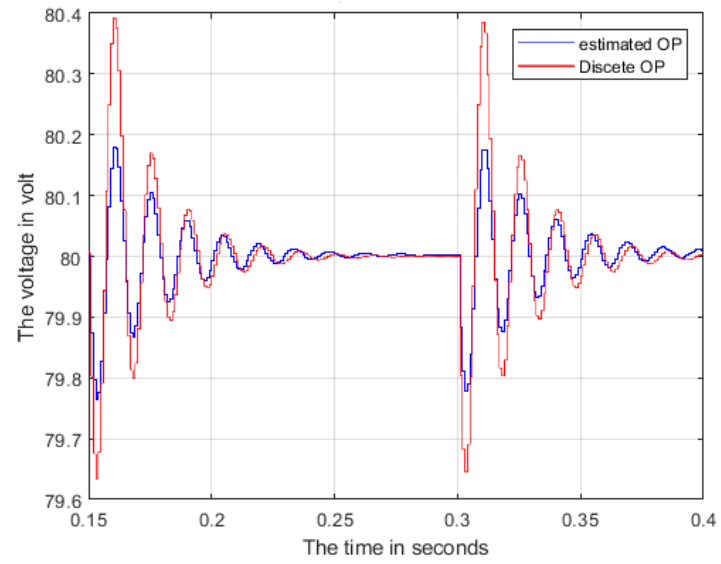

Fig. 25. Estimated and Discrete OP related to 0.01 PSD and $100 \mathrm{HZ}$ Frequncy.

TABLE XVIII.ESTIMATED PARAMETERS RELATED TO 0.01 PSD AND 100HZ FREQUENCY

\begin{tabular}{|c|c|c|c|c|}
\hline \multirow{3}{*}{ q-operator } & \multicolumn{4}{|c|}{ Estimated parameters in both transfer functions } \\
\hline & \multicolumn{2}{|c|}{$G E_{\operatorname{dis}(q)}$} & \multicolumn{2}{|c|}{$G E_{R e f(q)}$} \\
\hline & $A(q)$ & $B(q)$ & $A(q)$ & $B(q)$ \\
\hline$q^{0}$ & 1 & 0 & 1 & 0 \\
\hline$q^{-1}$ & -1.80 & -0.014765 & -2.6169 & -0.0029 \\
\hline$q^{-2}$ & 1.0196 & 0.0173581 & 2.4341 & 0.0142 \\
\hline$q^{-3}$ & -0.0501 & -0.00252 & -0.7972 & 0.0086 \\
\hline
\end{tabular}

\section{b) Example 9}

In this example noise will assumed to be 0.03 Power spectral density with $200 \mathrm{~Hz}$, the flowing Fig. 26 shows the Received communicated noise input signal with 0.03 PSD and $200 \mathrm{HZ}$ frequency compared with the (not communicated signal) MATLAB input signal, the input signal here is the disturbance signal to the converter circuit and the other input which is the reference signal will be noise free.
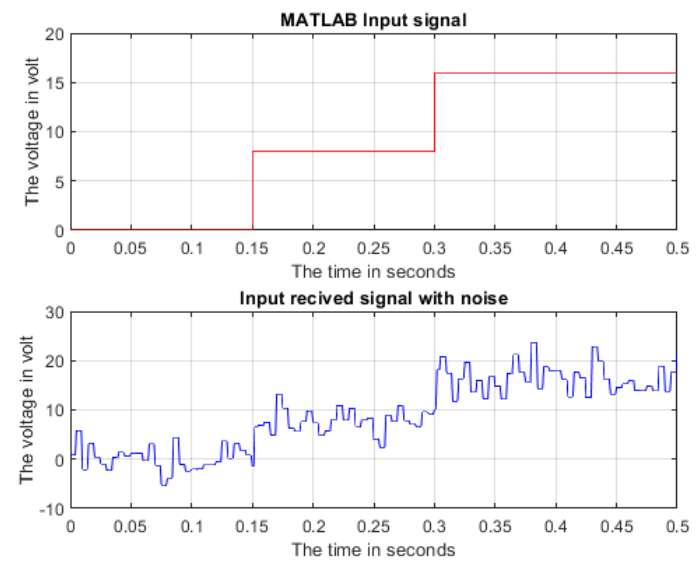

Fig. 26. Noisy Input related to 0.03 PSD and 200 HZ Frequncy.

Fig. 27 shows the Estimated OP and the Discrete OP.

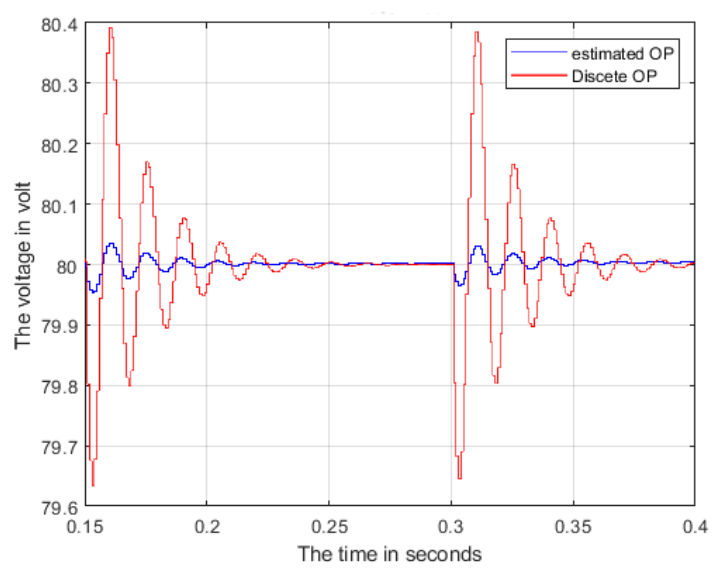

Fig. 27. Estimated and Discrete OP related to 0.03 PSD and $200 \mathrm{HZ}$ Frequncy.

It is clear from Fig. 27 that the estimated OP deviates greatly from the discrete OP, so that as the noise PSD and frequency increase, the identification process efficiency decreases, and high error is added to the system. From Fig. 36, the system characteristics (settling time, overshoot, oscillations number, etc.) can be measured but with even higher error from previous example.

The estimated parameters for both transfer function $G E_{\text {dis }(Z)}$ and $G E_{\text {Ref }(Z)}$ are shown in Table XIX.

TABLE XIX. Estimated PARAMETERS RELATED TO 0.03 PSD AND 200HZ FREQUENCY

\begin{tabular}{|c|l|l|l|l|}
\hline \multirow{2}{*}{ q-operator } & \multicolumn{3}{|c|}{ Estimated parameters in both transfer functions } \\
\cline { 2 - 5 } & \multicolumn{2}{|c|}{$G E_{\text {dis }(q)}$} & \multicolumn{2}{c|}{$G E_{\text {Ref }(q)}$} \\
\cline { 2 - 5 } & $A(q)$ & 0 & 1 & $0(q)$ \\
\hline$q^{0}$ & 1 & 0 & -2.6169 & -0.0029 \\
\hline$q^{-1}$ & -1.7041 & -0.0023 & 2.4341 & 0.0142 \\
\hline$q^{-2}$ & 0.8616 & 0.0024 & -0.7972 & 0.0086 \\
\hline$q^{-3}$ & 0.02905 & $-8.1281 \mathrm{e} 05$ & \multicolumn{3}{|c}{} \\
\hline
\end{tabular}

- Discussion

From the previous examples, it is clear that as the noise amplitude and frequency increase, so does the identification error, the identification error caused by noise can be seen as compression in the Y-axis; as the noise amplitude and frequency increase, the response will compress more; however, the system dynamic remains unchanged, so this error can be reduced or eliminated by tuning a proper controller that makes the identification process efficient.

Also, as shown in the Table XIX it clears that the parameters in both $\mathrm{A}(\mathrm{q}) \& \mathrm{~B}(\mathrm{q})$ change only in $G E_{\text {dis }(q)}$ but the $G E_{R e f(q)}$ remains the same in all example, the reasons of that is coming from adding the noise to the disturbance signal only making only the transfer $G E_{d i s(q)}$ changes as this transfer function describe the relation between the disturbance and the output, so that it is logical to change every time the disturbance noisy signal changes. 
On the other hand, $G E_{R e f(q)}$ which describe the relation between the reference input signal and the output voltage does not change as the input reference signal still the same in all examples with no noise added.

Future work can be conducted in many directions and applications. The use of OPC communication channel would have interesting future directions in many applications such as power [22-25], health [26-31], communication [32-37], AI applications [38-43], and optimization [44,45].

\section{CONCLUSION}

The identification process is highly dependent on the error associated with each factor. To determine whether the identification process is efficient or not, the effects or error associated with each factor are investigated to determine whether the identification process can truly provide a good estimate or not. As a result, before proceeding to the online detection, these factors must be optimized to produce the least amount of error possible, ensuring that the best parameters have been estimated.

\section{ACKNOWLEDGMENT}

The authors would like to express their gratitude to the support of Tafila Technical University as well as the support of the technical and administrative team at Samra Electric Power Company SEPCO, especially Eng. Mohammad Shiab and Eng. Yousef Balasya.

\section{REFERENCES}

[1] M. A. Obeidat, L. Y. Wang and Feng Lin, "On-line parameter estimation of PMDC motors using binary-valued speed measurements," 2012 IEEE Power and Energy Conference at Illinois, 2012, pp. 1-5, doi: 10.1109/PECI.2012.6184608.

[2] Obeidat, Mohammad, and Ali Hamad. "Applying two controller schemes to improve input tracking and noise reduction in DC-DC converters." Przegląd Elektrotechniczny 95 (2019).

[3] M. A. Obeidat, L. Y. Wang and F. Lin, "Online parameter estimation of PMDC motors using quantized output observations," 2012 IEEE Transportation Electrification Conference and Expo (ITEC), 2012, pp. 1-6, doi: 10.1109/ITEC.2012.6243416.

[4] M. A. Obeidat, L. Y. Wang and F. Lin, "Real-Time Parameter Estimation of PMDC Motors Using Quantized Sensors," in IEEE Transactions on Vehicular Technology, vol. 62, no. 7, pp. 2977-2986, Sept. 2013, doi: 10.1109/TVT.2013.2251431.

[5] Lopa, Shafinaz A., et al. "Design and simulation of DC-DC converters." International Research Journal of Engineering and Technology (IRJET) 3.01 (2016): 63-70.

[6] Raja MAZ and Chaudhary NI. Two-stage fractional least mean square identification algorithm for parameter estimation of CARMA systems. Signal Process 2015; 107: 327-339.

[7] Xu, Ling. "The parameter estimation algorithms based on the dynamical response measurement data." Advances in Mechanical Engineering 9.11 (2017): 1687814017730003.

[8] Diversi, Roberto, Roberto Guidorzi, and Umberto Soverini. "Identification of ARMAX models with noisy input and output." IFAC Proceedings Volumes 44.1 (2011): 13121-13126.

[9] Rachad, Sofia, Hicham Fouraiji, and Bahloul Bensassi. "Identification approach for a production system using ARX model." 2014 International Conference on Logistics Operations Management. IEEE, 2014.

[10] C. E. Shannon, A mathematical theory of communication, Bell System Technical Journal, vol. 27, pp. 379-423 and 623-656, (July and October, 1948)

[11] Ali ibraheem , "DC Chopper Circuits Modeling and Behaviour using Feedback and Feedforward Control",(2019)Tafila technical university
[12] linear approximation of a nonlinear function,(2021), $\mathrm{x}$ engineer,retrieved from $\mathrm{x}$-engineer.org

[13] Al-Alaoui, Mohamad Adnan. "Novel stable higher order s-to-z transforms." IEEE Transactions on Circuits and Systems I: Fundamental Theory and Applications 48.11 (2001): 1326-1329.

[14] Analytic Sciences Corporation. Technical Staff. (1974). Applied optimal estimation. Gelb, Arthur, 1937-. Cambridge, Mass.: M.I.T. Press. pp. 121. ISBN 0-262-20027-9. OCLC 960061

[15] R.H. Middleton \& G.C. Goodwin (1990). Digital control and estimation: a unified approach. p. 33f. ISBN 978-0132116657.

[16] OPC Foundation and MTConnect Institute Announce a Memorandum of Understanding". OPC Foundation. 2010-10-21. Archived from the opcfoundation.org on 2011-06-16. Retrieved 2010-10-26.

[17] Nicola, Marcel, Claudiu-Ionel Nicola, and M. Duta. "SCADA Systems Architecture Based on OPC and Web Servers and Integration of Applications for Industrial Process Control." International Journal of Control Science and Engineering 8.1 (2018): 13-21.

[18] Ayatollahi, Iman, et al. "Prototype OPC UA server for remote control of machine tools." Proceedings of International Conference on Innovative Technologies. 2013.

[19] Rohani, Mohd Faiz, et al. "OPC Protocol Application for Real-Time Carbon Monitoring System for Industrial Environment." International Journal of Electrical \& Computer Engineering (2088-8708) 7.2 (2017).

[20] KEPSERER OPC Server software,(2021),Kepware, Retrieved from www.kepware.com

[21] OPC Toolbox OPC Toolbox Read and write data from OPC servers and data historians,(2021),Mathworks ,Retrieved from /www.mathworks.com

[22] Mansour, A.M., Abdallah, J., Obeidat, M.A.,” An efficient intelligent power detection method for photovoltaic system," International Journal of Circuits, Systems and Signal Processing, vol. 14, pp. 686-699, 2020.

[23] M. A. Obeidat, M. Qawaqneh, A. M. Mansour and J. Abdallah, "Smart Distribution System using Fuzzy Logic Control," 2021 12th International Renewable Engineering Conference (IREC), Amman, Jordan, 2021, pp. 1-5.

[24] M. A. Obeidat, A. M. Mansour, B. Al Omaireen, J. Abdallah, F. Khazalah and M. Alaqtash, "A Deep Review and Analysis of Artificial Neural Network Use in Power Application with Further Recommendation and Future Direction," 2021 12th International Renewable Engineering Conference (IREC), Amman, Jordan, 2021, pp. $1-5$.

[25] A. M. Mansour, M. A. Obeidat and J. Abdallah, "A Novel Multi-agent Mechanism for Managing Electrical Power Smart Grids," 2021 12th International Renewable Engineering Conference (IREC), Amman, Jordan, 2021, pp. 1-6.

[26] Ayman M. Mansour, Murad M. Alaqtash, Mohammad Obeidat “Intelligent Classifiers of EEG Signals for Epilepsy Detection,” WSEAS Transactions on Signal Processing, vol. 15, 2019.

[27] Murad Alaqtash, Ayman M Mansour, Mohammad Obeidat, "Fuzzy Assessment Model for Functional Impairments in Human Locomotion”. IOSR-JECE, vol. 14, no. 1, Jan-Feb 2019.

[28] Ayman M. Mansour, "Intelligent E-Health System for Patient and Elderly People Monitoring Using Multi Agents System,” Jordan Journal of Electrical Engineering, vol. 4, no. 1, 2018.

[29] Ayman M. Mansour, "Decision Tree-Based Expert System for Adverse Drug Reaction Detection using Fuzzy Logic and Genetic Algorithm," International Journal of Advanced Computer Research (IJACR), vol. 8, no. 36, 2018.

[30] Mohammad A. Obeidat and Ayman M. Mansour, "EEG Based Epilepsy Diagnosis System using Reconstruction Phase Space and Naïve Bayes Classifier,” WSEAS Transactions on Circuits and Systems, vol. 17, 2018.

[31] Mansour, A.M., Obaidat, M.A. and Hawashin, B. Elderly people health monitoring system using fuzzy rule based approach. International Journal of Advanced Computer Research, vol. 4, no. 4, p.904. 2014.

[32] Ayman M. Mansour, "GSM based Vehicle-to-Vehicle Communication using Multi-Agent Intelligent System," WSEAS Transactions on Electronics, vol. 10, 2019. 
[33] Ayman M Mansour, “ Cooperative Multi-Agent Vehicle-to-Vehicle Wireless Network in a Noisy Environment," International Journal of Circuits, Systems and Signal Processing, vol. 15, 2021.

[34] Obeidat, M. A. Real-Time DC Servomotor Identification and Control of Mechanical Braking System for Vehicle to Vehicle Communication. International Journal of Computer Applications, 975, 8887.

[35] A. Mansour, H. Ying, P. Dews, Y. Ji and R. M. Massanari, "Identifying adverse drug reaction signal pairs by a multi-agent intelligent system with fuzzy decision model," 2012 Annual Meeting of the North American Fuzzy Information Processing Society (NAFIPS), Berkeley, CA, USA, 2012, pp. 1-6.

[36] A. Mansour et al., "Finding similar patients in a multi-agent environment," 2011 Annual Meeting of the North American Fuzzy Information Processing Society, El Paso, TX, USA, 2011, pp. 1-6.

[37] A. Mansour et al., "A multi-agent system for detecting adverse drug reactions," 2010 Annual Meeting of the North American Fuzzy Information Processing Society, Toronto, ON, Canada, 2010, pp. 1-6.

[38] Ayman M. Mansour, "Texture Classification using Naïve Bayes Classifier," International Journal of Computer Science and Network Security (IJCSNS), vol. 18, no. 1, January 2018

[39] D.A. Al Nadi and Ayman Mansour, "Independent Component Analysis (ICA) for texture classification", 5th International Multi-Conference on Signals and Devices, IEEE SSD, 2008.

[40] B. Hawashin et al., "Efficient Texture Classification Using Independent Component Analysis," 2019 IEEE Jordan International Joint Conference on Electrical Engineering and Information Technology (JEEIT), Amman, Jordan, pp. 544-547, 2019.

[41] Hawashin, B., Fotouhi, F. and Grosky, W., 2010, December. Diffusion maps: A superior semantic method to improve similarity join performance. In 2010 IEEE International Conference on Data Mining Workshops (pp. 9-16). IEEE.

[42] Hawashin, B., Aqel, D., AlZu’bi, S. and Jararweh, Y., 2019, June. Novel weighted interest similarity measurement for recommender systems using rating timestamp. In 2019 Sixth International Conference on Software Defined Systems (SDS) (pp. 166-170). IEEE.

[43] Hawashin, B., Aqel, D., Alzubi, S. and Elbes, M., 2020. Improving recommender systems using co-appearing and semantically correlated user interests. Recent Advances in Computer Science and Communications (Formerly: Recent Patents on Computer Science), 13(2), pp.240-247.

[44] Suhail Sharadqah, Ayman M Mansour, Mohammad A Obeidat, Ramiro Marbello and Soraya Mercedes Perez, "Nonlinear Rainfall Yearly Prediction based on Autoregressive Artificial Neural Networks Model in Central Jordan using Data Records: 1938-2018” International Journal of Advanced Computer Science and Applications(IJACSA), 12(2), 2021.

[45] Jafar.Abu Khait, Ayman M Mansour and Mohammad Obeidat, "Classification based on Gaussian-kernel Support Vector Machine with Adaptive Fuzzy Inference System,” Przegląd Elektrotechniczny., vol 5, pp 16-24, 2018. 